\title{
Overexpression of 14-3-3 $\zeta$ in lung tissue predicts an improved outcome in patients with lung adenocarcinoma
}

\author{
MAN LI ${ }^{1,2^{*}}$, HAILING LU ${ }^{1 *}$, XIAOLIAN LIU ${ }^{1,3^{*}}$, QINGWEI MENG ${ }^{1}$, YANBIN ZHAO ${ }^{1}$, \\ XUESONG CHEN ${ }^{1}$, JING HU ${ }^{1}$, WEI LIU ${ }^{1}$ and $\mathrm{LI} \mathrm{CAI}^{1}$ \\ ${ }^{1}$ The Fourth Department of Medical Oncology; ${ }^{2}$ Department of Endoscopy, Harbin Medical \\ University Cancer Hospital, Harbin, Heilongjiang 150040; ${ }^{3}$ Department of General \\ Oncology, Weihai Municipal Hospital, Weihai, Shandong 264200, P.R. China
}

Received January 20, 2016; Accepted June 2, 2017

DOI: $10.3892 / \mathrm{ol} .2018 .8742$

\begin{abstract}
One of the factors limiting the survival rate of patients with lung cancer is the high risk for recurrence following surgical resection. Previous studies indicate that $14-3-3 \zeta$ is a central cellular hub protein that regulates multiple signaling pathways involved in cancer progression. The present study evaluated the prognostic significance of $14-3-3 \zeta$ in patients with lung adenocarcinoma. The expression of 14-3-3 $\zeta$ and E-cadherin, an important protein involved in the epithelial-mesenchymal transition, was evaluated by immunohistochemistry in lung tumor tissues and adjacent normal lung tissues resected from 123 patients with lung adenocarcinoma. The correlation between the two proteins, their association with clinicopathological features and their prognostic significance were subsequently analyzed. Within these parameters, an overall survival (OS) prediction model was constructed using multivariate Cox proportional hazards regression. The expression of 14-3-3 $\zeta$ was upregulated in lung adenocarcinoma, in contrast to E-cadherin, which was downregulated in lung adenocarcinoma tissues compared with normal tissues. In addition, the expression of 14-3-3 $\zeta$ was positively correlated with that of E-cadherin $(\mathrm{r}=0.256, \mathrm{P}=0.012)$ and differentiation $(\mathrm{P}<0.001)$. Increased
\end{abstract}

Correspondence to: Dr Li Cai, The Fourth Department of Medical Oncology, Harbin Medical University Cancer Hospital, 150 Haping Road, Harbin, Heilongjiang 150040, P.R. China

E-mail: caili@ems.hrbmu.edu.cn

${ }^{*}$ Contributed equally

Abbreviations: EMT, epithelial mesenchymal transition; OS, overall survival; NSCLC, non-small cell lung cancer; E-cadherin, epithelial-cadherin; Tcf/Lef, T-cell factor/lymphoid enhancer factor; TGF $\beta$, transforming growth factor- $\beta$; ZFHX1B, Zinc finger homeobox 1B; Raf-CRD, Raf-1 cysteine-rich domain; ADAM, a disintegrin and metalloproteinase; EOC, epithelial ovarian carcinoma

Key words: 14-3-3ל, E-cadherin, lung adenocarcinoma, immunohistochemistry
E-cadherin expression was indicative of smaller tumor size and greater differentiation, and the overexpression of 14-3-3 $\zeta$ and E-cadherin were associated with longer OS $(\mathrm{P}=0.010$ and $\mathrm{P}=0.006$, respectively). Finally, a multivariate analysis revealed that TNM stage and 14-3-3 $\zeta$ were independent prognostic indicators $(\mathrm{P}<0.001$ and $\mathrm{P}=0.026$, respectively). 14-3-3 $\zeta$ may function as a tumor suppressor associated with E-cadherin upregulation and could be used as a prognostic biomarker for resected lung adenocarcinoma. These findings provide a novel insight on potential intervention strategies for patients with lung cancer.

\section{Introduction}

Lung cancer is one of the most common causes of cancer-associated mortality worldwide (1). As the most common histology of non-small cell lung cancer (NSCLC), lung adenocarcinoma has a poorer prognosis compared with squamous cell carcinoma due to its more rapid development and higher recurrence rate (2). Following surgical resection, even very early stage patients should be followed closely due to the high risk of recurrence (3). Molecular prognostic markers for recurrence have been extensively investigated (4). Novel prognostic gene expression signatures in lung adenocarcinoma should be confirmed using data sets containing information regarding patients divided into high- and low-risk groups with distinct overall survival rates. 14-3-3 , a subtype of the 14-3-3 protein family, is widely expressed in a number of types of cancer (5), and serves a critical role in tumorigenesis and tumor progression by interacting with $\sim 100$ key cellular proteins involved in numerous physiological processes, including intracellular signaling, cell cycle control, apoptosis and transcriptional regulation (6). Further evidence suggests that 14-3-3 $\zeta$ may be specifically dysregulated in tumors (7). A number of cellular proteins targeted by 14-3-3 $\zeta$ are involved in tumor development and progression; however, the specific molecular mechanisms underlying these associations remain unclear. Lu et al (8) suggested that 14-3-3\} overexpression promotes the activation of the transforming growth factor- $\beta / \mathrm{Smad}$ (TGF $\beta / \mathrm{Smad})$ signaling pathway via the upregulation of Zinc finger homeobox 1B (ZFHX1B). Chen et al (9) identified 14-3-3\} in complex with $\beta$-catenin as a potential promoter of metastasis 
in lung cancer. In addition, downregulation of $14-3-3 \xi$ has been reported to suppress anchorage-independent growth of lung cancer cells through the activation of anoikis via the upregulation of Bcl-2-associated agonist of cell death (Bad) and Bcl-2-like protein 11 coupled with a decrease of Mcl-1, resulting in the subsequent activation of Bcl-2-associated $\mathrm{X}$ protein (10). Additional studies have demonstrated that the phosphorylation of $14-3-3 \zeta$ by c-Jun N-terminal kinase releases the pro-apoptotic proteins Bad and Forkhead box protein O3a from 14-3-3 , promoting apoptosis via the mitochondrial apoptotic pathway and antagonizing the effects of RAC-alpha serine/threonine-protein kinase signaling $(11,12)$.

Reduced 14-3-3 $\zeta$ levels have been demonstrated to increase the $G_{1} / G_{0}$-phase ratio, and decrease the $S$-phase fraction and the rate of DNA synthesis in cell cycle (13). However, increasing evidence challenges its putative malignant potential. Clark et al (14) reported that 14-3-35 interaction with the Raf-1 cysteine-rich domain (Raf-CRD) may serve in the negative regulation of Raf-1 function. In addition, 14-3-3 $\zeta$ was demonstrated to lead to the cytoplasmic enrichment of $\beta$-catenin, caused by a novel mechanism through which chibby (CBY) acts with $14-3-3 \zeta$ proteins to facilitate the nuclear export of $\beta$-catenin, and subsequently repressing the $\beta$-catenin-mediated Wnt signaling pathway (15). Zhu et al (16) demonstrated that the binding of 14-3-3 $\zeta$ and a disintegrin and metalloproteinase (ADAM) 22cyt enhanced cell adhesion by increasing the affinity of ADAM22 disintegrin to its receptor. Therefore 14-3-3 $\zeta$ interacts with a number of target proteins ranging from transcription factors to intracellular signaling molecules.

The present study focused on the potential role of 14-3-3 $\zeta$ as a candidate proto-oncogene, specifically in lung adenocarcinoma. Epithelial-cadherin (E-cadherin; encoded by CDH1) is a classical cadherin that is necessary for effective cell-cell adhesion (17). Loss of E-cadherin expression is a hallmark of the epithelial-mesenchymal transition (EMT), a process responsible for the increased invasiveness of tumor cells during tumorigenesis (18). Its downregulation during EMT can be due to promoter methylation or upregulation of transcriptional repressors, including snail, slug, twist, E12, E47, ZFHX1B and deltaEF1 (19). E-cadherin, traditionally known as a tumor suppressor gene, also regulates $\beta$-catenin signaling in the canonical Wnt signaling pathway (20) and its reduced expression has been observed in the majority of types of epithelial cancer, promoting tumor invasiveness and leading to poor patient prognosis (21). 14-3-3 $\zeta$ has been proposed to be a metastatic factor in lung cancer (22); however, the molecular mechanisms underlying this effect remain unknown. In the present study, the association between 14-3-3 $\xi$ and E-cadherin was investigated in lung adenocarcinoma.

\section{Materials and methods}

Patients and samples. The current retrospective study included 123 patients (67 males and 56 females) with lung adenocarcinoma who underwent surgical resection between January 2009 and October 2010 in Harbin Medical University Cancer Hospital (Harbin, China). Clinicopathological data were obtained by reviewing the relevant medical charts. None of patients received preoperative chemotherapy or radiotherapy. Primary cancers were classified according to the TNM staging system $(23,24)$ for lung cancer (American Joint Committee on Cancer Staging System, 7th Edition). Tumor and normal alveolar tissue specimens were collected in $10 \%$ formalin at room temperature for $24-48 \mathrm{~h}$ and embedded in paraffin for use in all experiments. The present study was approved by the Hospital Ethics Committee at the Harbin Medical University Cancer Hospital (Harbin, China). All investigators involved in the study, apart from the study statistician, were blinded to patient outcome throughout all laboratory analyses.

Immunohistochemical staining for 14-3-3\} and E-cadherin. Immunohistochemical staining was performed using the streptavidin-peroxidase (S-P) method. The dewaxed sections $(4 \mu \mathrm{m})$ were baked in an oven $\left(70^{\circ} \mathrm{C}\right)$ for $3 \mathrm{~h}$. Endogenous peroxide was blocked using $3 \%$ hydrogen peroxide for $10 \mathrm{~min}$ at room temperature. Following three washes with PBS, the sections were incubated with blocking serum (OriGene Technologies, Inc., Rockville, MD, USA) for between 10 and $20 \mathrm{~min}$ at room temperature. Sections were washed and then incubated overnight at $4{ }^{\circ} \mathrm{C}$ with rabbit polyclonal antibodies against 14-3-3 5 (dilution, 1:30; sc-732; Santa Cruz Biotechnology, Inc., Dallas, TX, USA) and rabbit polyclonal antibodies against E-cadherin (dilution, 1:30; sc-7,870; Santa Cruz Biotechnology, Inc.). Following another wash step, the sections were incubated with horseradish peroxidase-conjugated secondary antibody (PV-6,000; OriGene Technologies, Inc.) for $30 \mathrm{~min}$ at room temperature and the reaction products were visualized with diaminobenzidine. The sections were then counterstained with hematoxylin for 7-10 sec at room temperature. Immunohistochemical evaluation was performed independently by two pathologists using an Olympus microscope (BX51; Olympus Corporation, Tokyo, Japan) and immunohistochemical staining was scored according to the following criterion:,$- 0-5 \%$ of the cells stained;,$+ 6-25 \%$ of the cells stained;,$++ 26-50 \%$ of the cells stained;,$+++ 51-75 \%$ of the cells stained; and,$++++ 76-100 \%$ of the cells stained. Immunohistochemistry expression scores of $0 \leq$ score $\leq 1+$; and $2+\leq$ score $\leq 4+$ were classified as low expression and strong expression, respectively.

Statistical analysis. The data were subjected to statistical analysis using SPSS software (version 21.0; IBM Corp., Armonk, $\mathrm{NY}$, USA). $\mathrm{P}<0.05$ was considered to indicate a statistically significant difference. The $\chi^{2}$ test was used to compare patient clinicopathological characteristics with the expression of 14-3-3 $\zeta$ and E-cadherin. Correlation between expression levels was studied using Kendall's tau-b (K). Survival analysis was performed using the Kaplan-Meier estimator method and Log-rank test. Independent risk factors of prognosis were analyzed using the multivariate Cox proportional hazards model. Variables were adopted for their prognostic significance $(\mathrm{P}<0.05)$ in univariate analysis using forward, stepwise selection (forward likelihood ratio).

\section{Results}

Expression of 14-3-3\} and E-cadherin in lung adenocarcinoma tissues. The expression of 14-3-3 $\zeta$ protein in lung adenocarcinoma samples (Fig. 1A and B; magnification, $\mathrm{x} 400$ ) 
A

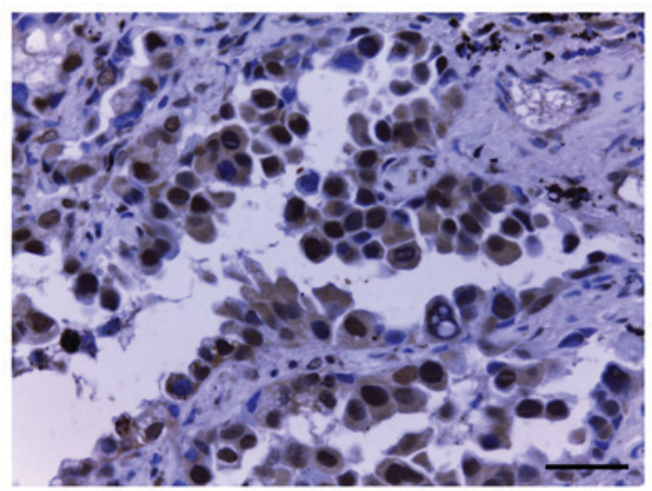

C

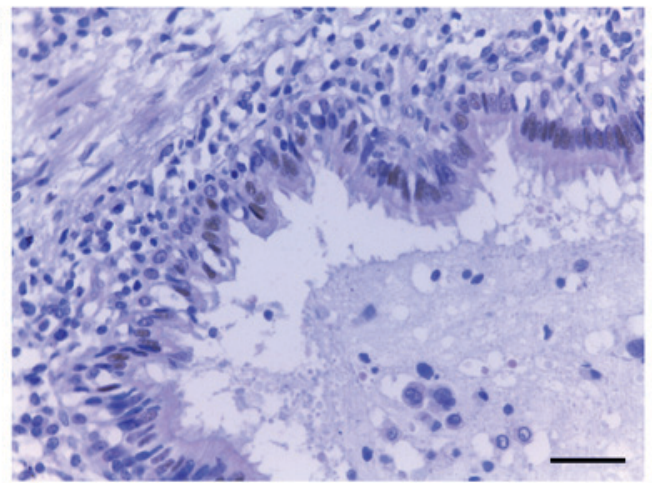

B
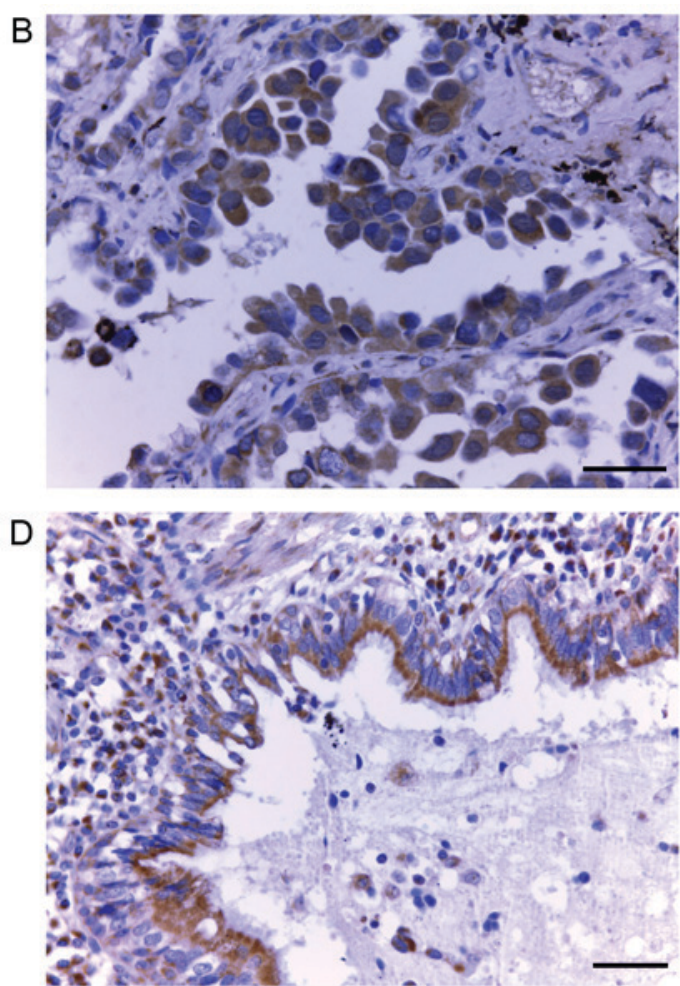

Figure 1. Immunohistochemical staining for 14-3-3 $\zeta$ and E-cadherin in lung adenocarcinoma tissues. (A) Representative picture of lung adenocarcinoma tissue showing positive 14-3-3ל staining. Scale bar, $20 \mu \mathrm{m}$. (B) Representative picture of lung adenocarcinoma tissue showing positive E-cadherin staining. Scale

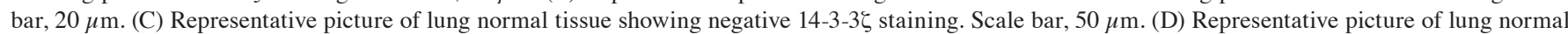
tissue showing positive E-cadherin staining. Scale bar, $50 \mu \mathrm{m}$.

Table I. Expression of 14-3-3 $\zeta$ and E-cadherin in lung adenocarcinoma tissues.

\begin{tabular}{|c|c|c|c|c|c|c|}
\hline \multirow[b]{2}{*}{ Tissue } & \multicolumn{2}{|c|}{$14-3-3 \zeta$} & \multirow[b]{2}{*}{ P-value } & \multicolumn{2}{|c|}{ E-cadherin } & \multirow[b]{2}{*}{ P-value } \\
\hline & Low (n) & High (n) & & Low (n) & $\operatorname{High}(\mathrm{n})$ & \\
\hline Normal & 57 & 26 & 0.001 & 27 & 71 & 0.537 \\
\hline Lung adenocarcinoma & 47 & 58 & & 33 & 69 & \\
\hline
\end{tabular}

High expression rate of 14-3-3 $\zeta$ or E-cadherin between normal tissue and lung adenocarcinoma was compared using the $\chi^{2}$ test.

and adjacent normal alveolar tissues (Fig. 1C and D; magnification, x200) was analyzed by immunohistochemistry. A total of 18 14-3-3 $\zeta$ and 21 E-cadherin samples were excluded due to damage or cytolysis of the paraffin block. Positive immunohistochemical staining for 14-3-3\} was primarily observed in the cytoplasm and membrane (Fig. 1A), but certain tissues also exhibited nuclear localization of 14-3-3 . Cytoplasmic and nuclear expression were observed concurrently in one specimen. Strong expression of $14-3-3 \xi$ was observed in $55.24 \%(58 / 105)$ of lung adenocarcinoma tissues, compared with only $31.33 \%(26 / 83)$ of adjacent normal alveolar tissues $(\mathrm{P}=0.001)$. On the contrary, strong expression of E-cadherin was more prevalent in normal tissues compared with lung adenocarcinoma tissues (72.44 vs. $67.65 \%$, respectively, $\mathrm{P}=0.537$; Table I).

Correlation between clinicopathological features and the expression of 14-3-3\} and E-cadherin. Data from the correlative analysis of 14-3-3 - expression and the clinicopathological characteristics of patients with lung adenocarcinoma are summarized in Table II. Comparisons of 14-3-3 $\zeta$ expression with clinicopathological characteristics demonstrated that 14-3-3 5 overexpression correlated with differentiation $(\mathrm{P}<0.001)$ but not with any other included clinical parameter. Increased E-cadherin expression was indicative of smaller tumor size $(\mathrm{P}=0.018)$ and greater differentiation $(\mathrm{P}=0.028)$. In addition, the expression of $14-3-3 \zeta$ was positively correlated with that of E-cadherin $(\mathrm{P}=0.012)$.

Prediction of survival in lung adenocarcinoma patients by 14-3-3\} and E-cadherin. To elucidate the prognostic role of 14-3-3 $\zeta$ in patients with lung adenocarcinoma, overall survival (OS) rates were estimated using Kaplan-Meier survival curves. Patients with high expression of 14-3-3 $\zeta$ were observed to have a longer OS period compared with those with low expression $(\mathrm{P}=0.010$; Fig. 2). Similarly, 
Table II. Correlation between clinicopathological characteristics and the expression of 14-3-3 $\zeta$ and E-cadherin.

\begin{tabular}{|c|c|c|c|c|c|c|}
\hline \multirow[b]{2}{*}{ Characteristics } & \multicolumn{2}{|c|}{$14-3-3 \zeta(n=105)^{c}$} & \multirow[b]{2}{*}{ P-value } & \multicolumn{2}{|c|}{ E-cadherin $(n=102)^{c}$} & \multirow[b]{2}{*}{ P-value } \\
\hline & Low (n) & Strong (n) & & Low (n) & Strong $(\mathrm{n})$ & \\
\hline Sex & & & 0.249 & & & 0.077 \\
\hline Male & 28 & 28 & & 21 & 31 & \\
\hline Female & 19 & 30 & & 12 & 38 & \\
\hline Age & & & 0.421 & & & 0.627 \\
\hline$\leq 55$ & 19 & 28 & & 16 & 37 & \\
\hline$>55$ & 28 & 30 & & 17 & 32 & \\
\hline Tumor size & & & 0.213 & & & $0.018^{\mathrm{b}}$ \\
\hline$\leq 3$ & 17 & 28 & & 9 & 36 & \\
\hline$>3$ & 30 & 30 & & 24 & 33 & \\
\hline Node status & & & 0.555 & & & 0.300 \\
\hline Negative & 29 & 39 & & 17 & 43 & \\
\hline Positive & 18 & 19 & & 16 & 26 & \\
\hline Differentiation & & & $<0.001^{\mathrm{a}}$ & & & $0.028^{\mathrm{b}}$ \\
\hline Good/moderate & 17 & 43 & & 11 & 39 & \\
\hline Poor & 30 & 15 & & 22 & 30 & \\
\hline TNM Stage & & & 0.805 & & & 0.954 \\
\hline I & 15 & 21 & & 10 & 23 & \\
\hline II & 13 & 13 & & 7 & 14 & \\
\hline III & 19 & 24 & & 16 & 32 & \\
\hline Chemotherapy & & & 0.296 & & & 0.106 \\
\hline No & 18 & 16 & & 14 & 17 & \\
\hline Yes & 29 & 42 & & 19 & 52 & \\
\hline E-cadherin expression ${ }^{\mathrm{d}}$ & & & $0.012^{\mathrm{e}}$ & & & \\
\hline Low or negative & 22 & 14 & & & & \\
\hline Strong & 25 & 44 & & & & \\
\hline
\end{tabular}

${ }^{\mathrm{a}} \mathrm{P}<0.001$ and ${ }^{\mathrm{b}} \mathrm{P}<0.05$. ${ }^{\mathrm{c}} \mathrm{A}$ total of $1814-3-3 \zeta$ and $21 \mathrm{E}$-cadherin samples were excluded due to damage or cytolysis of the paraffin block. ${ }^{\mathrm{d}}[0$ (negative) $\leq$ score $\leq 1+]$ and $[2+\leq$ score $\leq 3+]$ represent low positive or negative and strong positive scores, respectively, for 14-3-3 3 . $[0$ (negative) $\leq$ score $\leq 1+]$ and $[2+\leq$ score $\leq 3+]$ represent low positive or negative and strong positive scores, respectively, for E-cadherin. All of the cut-off points contributed to acquiring the optimum balance ratio between negative and positive. ${ }^{\mathrm{e}} \mathrm{Kendall}$ 's tau-b (K) correlation analysis .

A

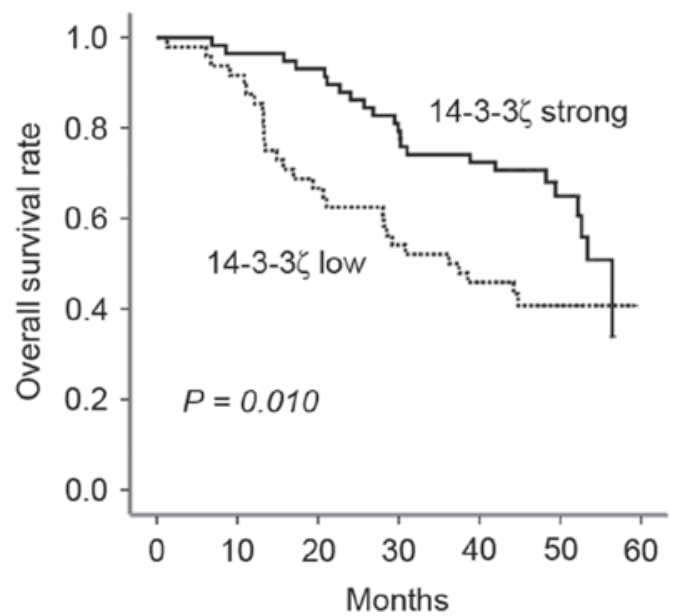

B

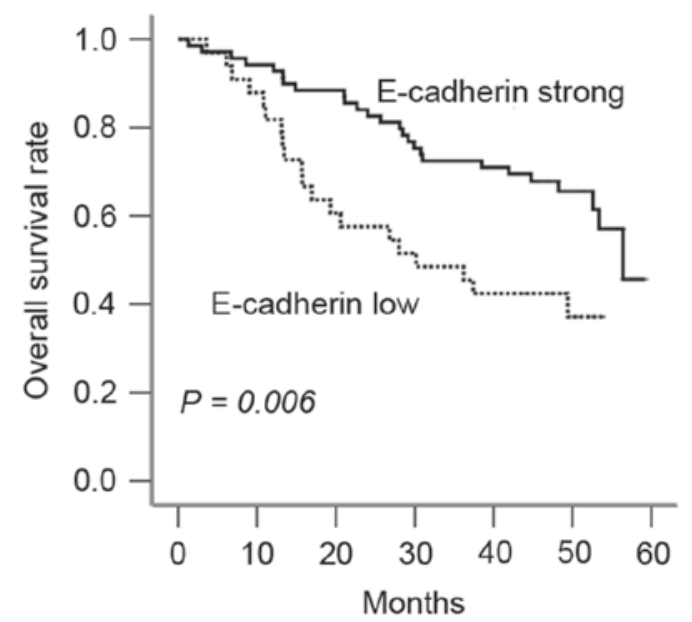

Figure 2. Kaplan-Meier survival curves of patients with lung adenocarcinoma. Overall survival rate of patients with low or high expression of (A) $14-3-3 \zeta$ and (B) E-cadherin. 
Table III. Univariate analysis of overall survival in patients with lung adenocarcinoma.

\begin{tabular}{lcr}
\hline Characteristics & HR $(95 \% \mathrm{CI})^{\mathrm{a}}$ & P-value \\
\hline Age & $0.694(0.415,1.163)$ & 0.165 \\
Gender & $0.550(0.322,0.938)$ & 0.028 \\
TNM stage & $1.733(1.259,2.386)$ & 0.001 \\
Node status & $3.552(1.938,6.510)$ & $<0.001$ \\
Tumor size & $1.430(0.829,2.468)$ & 0.199 \\
Differentiation & $0.692(0.481,0.996)$ & 0.048 \\
14-3-3 expression & $0.754(0.575,0.990)$ & 0.042 \\
E-cadherin expression & $0.729(0.546,0.974)$ & 0.032 \\
Chemotherapy & $0.651(0.388,1.091)$ & 0.103
\end{tabular}

${ }^{a}$ Variables were adopted for their prognostic significance $(\mathrm{P}<0.05)$ in univariate analysis using forward, stepwise selection (forward likelihood ratio). CI, confidence interval; HR, hazard ratio; OS, overall survival.

Table IV. Multivariate analysis of overall survival in patients with lung adenocarcinoma.

\begin{tabular}{lcr}
\hline Characteristics & HR $(95 \% \mathrm{CI})^{\mathrm{a}}$ & P-value \\
\hline Gender & & 0.146 \\
TNM stage & $2.209(1.469,3.320)$ & $<0.001$ \\
Node status & & 0.151 \\
Differentiation & $0.692(0.500,0.956)$ & 0.057 \\
14-3-3 expression & & 0.026 \\
E-cadherin expression & & 0.598 \\
\hline
\end{tabular}

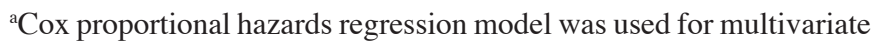
analysis. CI, confidence interval; HR, hazard ratio; OS, overall survival.

increased E-cadherin was indicative of an improved prognosis $\mathrm{P}=0.006$ ).

14-3-3̧ expression as an independent prognostic factor in resected lung adenocarcinoma patients. Univariate and multivariate analyses were performed using the Cox proportional hazards model to evaluate the impact of 14-3-3 5 expression and pathological factors on the prognosis of patients with lung adenocarcinoma (Table III). Multivariate analyses demonstrated that $14-3-3 \zeta$ expression $(\mathrm{P}=0.026)$ and TNM stage $(\mathrm{P}<0.001)$ were associated with $\mathrm{OS}$, which suggests that 14-3-3 $\zeta$ may act as a prognostic indicator for OS of patients with lung adenocarcinoma (Table IV).

\section{Discussion}

E-cadherin is a tumor suppressor protein that is used as a prognostic marker for cancer. Downregulation of E-cadherin during cancer progression correlates with aggressive tumor behavior and a poor prognosis $(25,26)$. Conversely, high expression of E-cadherin has been demonstrated to reduce tumor progression and invasiveness in addition to the formation of metastases $(21,27-30)$. The results from the present study demonstrated that the overexpression of $14-3-3 \xi$ was significantly associated with positive E-cadherin expression in tissue specimens from patients with lung adenocarcinoma and was a prognostic factor, which is in agreement with a number of previous studies that have suggested this association $(14,15,31,32)$. Notably, Raf-1 is a critical effector of Ras signaling and transformation. Activating Racl and the subsequent phosphorylation of Raf and mitogen-activated protein kinase kinase results in constitutive, anchorage-independent activation of the Ras/mitogen-activated protein kinase/extracellular signal-regulated kinase signaling pathway, which elevates the expression of the master regulator Snail 1, thereby inducing transcriptional repression of E-cadherin mRNA (33). Clark et al (14) indicated that 14-3-3 $\zeta$ interaction with the Raf-CRD may serve a role in the negative regulation of Raf-1 function by facilitating the dissociation of 14-3-3 $\zeta$ from the $\mathrm{NH} 2$ terminus of Raf-1, thus leading to enhanced E-cadherin expression. Additionally, when $\beta$-catenin translocates into the nucleus, it interacts with the Tcf/Lef family to activate the canonical Wnt signaling pathway, switching on the transcription of certain target genes and resulting in the proliferation and metastasis of tumor cells $(34,35)$. Previously, 14-3-3 was demonstrated to cause the cytoplasmic enrichment of $\beta$-catenin, potentially through interaction with CBY1, and to subsequently repress the $\beta$-catenin-mediated Wnt signaling pathway, which is responsible for activating EMT and is characteristic of E-cadherin loss (15). Therefore, 14-3-3\} appears to inhibit tumor cell invasion and metastasis indirectly (15). In addition, 14-3-3 $\zeta$ overexpression has been demonstrated to promote TGF $\beta /$ Smad signaling pathway activation (8), although a reduction of E-cadherin expression and induction of EMT is not always observed, according to certain studies $(36,37)$. Ahn et al $(38)$ indicated that $S m a d 3$ regulates, at the transcriptional level, miR-200 family members, which themselves regulate $\mathrm{ZEB} 1$ and ZEB2, transcriptional repressors of E-cadherin, at the posttranscriptional level. Mise et al (39) identified that Smad3-mediated TGF- $\beta$ signaling targeted the zyxin gene, mediating cancer cell motility and EMT during lung cancer progression by regulating cell-cell junctions, integrin 5 expression and cell-extracellular matrix adhesion. Therefore, data from the present study provides novel insights into the indirect regulation of E-cadherin by 14-3-3 $\zeta$ via TGF $\beta /$ Smad-mediated cancer cell adhesion and motility. Notably, Snail 1, one of the major transcriptional suppressors of E-cadherin mRNA, exhibits a repressive effect on the expression of 14-3-3 family members, including the zeta form (31), which is in agreement with the previously suggested role of 14-3-3 $\zeta$ in promoting E-cadherin expression (32). Therefore, the positive correlation of 14-3-3 $\zeta$ with E-cadherin observed in the present study implies a role for $14-3-3 \xi$ as a metastatic inhibitor.

Nevertheless, contradictory reports do exist. Zhao et al (40) demonstrated that that $14-3-3 \zeta$ and Hsp27 negatively correlate with E-cadherin expression in NSCLC. In addition, 14-3-3 $\zeta$ overexpression has been observed to reduce cell adhesion by activating the TGF $\beta /$ Smad signaling pathway, leading to ZFHX1B/SIP-1 upregulation, E-cadherin loss and EMT 
in breast cancer (8). In accordance with the presumed role of $14-3-3 \zeta$ as a metastatic inhibitor, western blot analysis of human lung giant cell carcinoma cells revealed that $14-3-3 \xi$ expression was more prevalent in poorly metastatic cells than in highly metastatic cells, and that cells that overexpress 14-3-3 $\zeta$ were reported to exhibit a lower proliferative ability, higher adhesive ability and lower migratory ability compared with cells transfected with control vector (41). In addition, 14-3-3 $\zeta$ expression was observed to be increased in lung cancer cells treated with $\mathrm{Rg} 3$, a metastasis suppressor, leading to the inhibition of cell invasiveness and metastasis (42). Metastasis is not the only malignant characteristic of lung cancer, but it is the primary cause of worsening prognosis and high mortality rate (43).

The results from the present study demonstrated that strong $14-3-3 \zeta$ staining was associated with greater differentiation and longer OS, and was determined to be an independent prognostic factor for OS according to multivariate analysis. Supporting the data from the present study, the positive interaction between 14-3-3 $\zeta$ and another metastasis-associated adhesion molecule ADAM22 has been reported (16). Zhu et al (16) identified, for the first time, a novel interaction between 14-3-3 6 and ADAM22, a transmembrane protein containing disintegrin-like and metalloproteinase-like domains (44) and demonstrated that the binding of 14-3-3 $\xi$ to ADAM22cyt enhances cell adhesion by increasing the affinity of ADAM22 disintegrin to its receptor, therefore implying a potential role of the 14-3-3\} protein in the ADAM22-associated regulation of cell adhesion. Kobayashi et al (45) demonstrated that $14-3-3 \xi$ secreted by ascite monocytes/macrophages, which characteristically release a number of inflammatory cytokines and chemokines, is present in the malignant ascites of patients with epithelial ovarian carcinoma and could be taken up by tumor cells, implying a potential role for secreted $14-3-3 \zeta$ in the inhibition of tumor growth and proliferation. While these reports are in accordance with the data from the present study, much of the current literature proposes that the upregulated expression of $14-3-3 \xi$ is associated with high histological grade, lymph node metastasis and poor clinical outcome in certain types of cancer. Fan et al (46) suggested that increased $14-3-3 \zeta$ expression is positively correlated with a more advanced pathologic stage and grade of NSCLC, and was associated with worse overall and cancer-specific survival. Niemantsverdriet et al (7) reported that strong 14-3-3 $\xi$ staining was associated with reduced OS and was determined to be an independent prognostic factor for disease-free survival by multivariate analysis. Further studies are required to explain why contradictory data exists regarding 14-3-3६ in tumorigenesis and tumor progression. The present study specifically focused on the metastatic impact of $14-3-3 \zeta$ in relatively early stages of resectable lung adenocarcinoma without distant metastasis, which is unlike the majority of the previous studies performed in lung cancer, which included a number of pathologies and advanced stage cancers $(46,47)$. 14-3-3 $\zeta$ overexpression exerts complex biological effects via its interaction with a number of different proteins in a spatial and a temporal fashion, emphasizing individual functions in diverse signaling pathways in various tumor types $(48,49)$. In addition, 14-3-3६ exhibits multiple, opposing roles, making the analysis of its effects in complex systems challenging. It should therefore be studied with a focus on controlled study parameters.

In conclusion, the increased expression of $14-3-3 \zeta$ was observed more frequently in patients with resectable lung adenocarcinoma with an improved prognosis and was positively associated with E-cadherin. Therefore, 14-3-3 may be a novel marker for predicting the prognosis of resectable lung adenocarcinoma. To identify the molecular mechanisms underlying this observation, a longitudinal study of a large population is required.

\section{Acknowledgements}

The authors of the present study would like to thank Ms. Xiaohui He for providing patient data and Dr. Jingshu Geng of the Medical Record Room and the Department of Pathology of Harbin Medical University Cancer Hospital respectively, for collecting tissue specimens.

\section{Funding}

The present study was supported by the National Natural Science Foundation of China (grant nos. 30772540 and 81172214 to L.C. and 81301991 to Y.Z.).

\section{Availability of data and materials}

The datasets used and/or analyzed during the current study are available from the corresponding author on reasonable request.

\section{Authors' contributions}

ML and LC contributed to the conception and design of the study. XL, HL, YZ, XC, JH and WL performed the experiment. QM and XL performed the statistical analysis. ML wrote the manuscript. QM revised the manuscript. All authors read and approved the final manuscript.

\section{Ethics approval and consent to participate}

This study was approved by the Ethics Committee of Harbin Medical University Cancer Hospital. All patients provided written informed consent.

\section{Consent for publication}

As all data was anonymized, this study does not contain any individual person's data in any form (including individual details, images, or videos) and accordingly consent for publication was exempted.

\section{Competing interests}

The authors declare that they have no competing interests.

\section{References}

1. Siegel R, Naishadham D and Jemal A: Cancer statistics, 2012. CA Cancer J Clin 62: 10-29, 2012. 
2. Brundage MD, Davies D and Mackillop WJ: Prognostic factors in non-small cell lung cancer: A decade of progress. Chest 122: 1037-1057, 2002.

3. Choi PJ, Jeong SS and Yoon SS: Prediction and prognostic factors of post-recurrence survival in recurred patients with early-stage NSCLC who underwent complete resection. J Thorac Dis 8: 152-160, 2016.

4. Botling J, Edlund K, Lohr M, Hellwig B, Holmberg L, Lambe M, Berglund A, Ekman S, Bergqvist M, Pontén F, et al: Biomarker discovery in non-small cell lung cancer: Integrating gene expression profiling, meta-analysis, and tissue microarray validation. Clin Cancer Res 19: 194-204, 2013.

5. Yang X, Cao W, Zhang L, Zhang W, Zhang X and Lin $\mathrm{H}$ : Targeting 14-3-3zeta in cancer therapy. Cancer Gene Ther 19: $153-159,2012$

6. La Porta S, Roth L, Singhal M, Mogler C, Spegg C, Schieb B, Qu X, Adams RH, Baldwin HS, Savant S and Augustin HG Endothelial Tie1-mediated angiogenesis and vascular abnormalization promote tumor progression and metastasis. J Clin Invest 128: 834-845, 2018.

7. Niemantsverdriet $M$, Wagner $K$, Visser $M$ and Backendorf $C$ : Cellular functions of 14-3-3 zeta in apoptosis and cell adhesion emphasize its oncogenic character. Oncogene 27: 1315-1319, 2008.

8. Lu J, Guo H, Treekitkarnmongkol W, Li P, Zhang J, Shi B Ling C, Zhou X, Chen T, Chiao PJ, et al: 14-3-3zeta Cooperates with ErbB2 to promote ductal carcinoma in situ progression to invasive breast cancer by inducing epithelial-mesenchymal transitition. Cancer Cell 16: 195-207, 2009.

9. Chen CH, Chuang SM, Yang MF, Liao JW, Yu SL and Chen JJ: A novel function of YWHAZ/ $\beta$-catenin axis in promoting epithelial-mesenchymal transition and lung cancer metastasis. Mol Cancer Res 10: 1319-1331, 2012.

10. Li Z, Zhao J, Du Y, Park HR, Sun SY, Bernal-Mizrachi L, Aitken A, Khuri FR and Fu H: Down-regulation of 14-3-3zeta suppresses anchorage-independent growth of lung cancer cells through anoikis activation. Proc Natl Acad Sci USA 105: 162-167, 2008.

11. Neal CL, Yao J, Yang W, Zhou X, Nguyen NT, Lu J, Danes CG, Guo H, Lan KH, Ensor J, et al: 14-3-3zeta overexpression defines high risk for breast cancer recurrence and promotes cancer cel survival. Cancer Res 69: 3425-3432, 2009.

12. Choi JE, Hur W, Jung CK, Piao LS, Lyoo K, Hong SW, Kim SW, Yoon HY and Yoon SK: Silencing of 14-3-3६ over-expression in hepatocellular carcinoma inhibits tumor growth and enhances chemosensitivity to cis-diammined dichloridoplatium. Cancer Lett 303: 99-107, 2011.

13. Cao W, Yang X, Zhou J, Teng Z, Cao L, Zhang X and Fei Z: Targeting 14-3-3 protein, difopein induces apoptosis of human glioma cells and suppresses tumor growth in mice. Apoptosis 15 230-241, 2010

14. ClarkGJ,Drugan JK,Rossman KL,CarpenterJW,Rogers-GrahamK, Fu H, Der CJ and Campbell SL: 14-3-3 zeta negatively regulates raf-1 activity by interactions with the Raf-1 cysteine-rich domain J Biol Chem 272: 20990-20993, 1997.

15. Li FQ, Mofunanya A, Harris K and Takemaru K: Chibby cooperates with 14-3-3 to regulate beta-catenin subcellular distribution and signaling activity. J Cell Biol 181: 1141-1154, 2008.

16. Zhu Pc, Sun Y, Xu R, Sang Y, Zhao J, Liu G, Cai L, Li C and Zhao S: The interaction between ADAM 22 and 14-3-3zeta: Regulation of cell adhesion and spreading. Biochem Biophys Res Commun 301: 991-999, 2003.

17. Daugaard I, Sanders KJ, Idica A, Vittayarukskul K, Hamdorf M, Krog JD, Chow R, Jury D, Hansen LL, Hager H, et al: miR-151a induces partial EMT by regulating E-cadherin in NSCLC cells. Oncogenesis 6: e366, 2017.

18. Li S, Xu F, Zhang J, Wang L, Zheng Y, Wu X, Wang J, Huang Q and Lai M: Tumor-associated macrophages remodeling EMT and predicting survival in colorectal carcinoma. Oncoimmunology 7 e1380765, 2017.

19. Peinado H, Portillo F and Cano A: Transcriptional regulation of cadherins during development and carcinogenesis. Int J Dev Biol 48: 365-375, 2004

20. Taddei ML, Chiarugi P, Cirri P, Buricchi F, Fiaschi T, Giannoni E Talini D, Cozzi G, Formigli L, Raugei G and Ramponi G: Beta-catenin interacts with low-molecular-weight protein tyrosine phosphatase leading to cadherin-mediated cell-cell adhesion increase. Cancer Res 62: 6489-6499, 2002.

21. Chen JJ, Peck K, Hong TM, Yang SC, Sher YP, Shih JY, Wu R, Cheng JL, Roffler SR, Wu CW and Yang PC: Global analysis of gene expression in invasion by a lung cancer model. Cancer Res 61: 5223-5230, 2001
22. Guo Y, Yin J, Zha L and Wang Z: Clinicopathological significance of platelet-derived growth factor $B$, platelet-derived growth factor receptor- $\beta$ and $\mathrm{E}$-cadherin expression in gastric carcinoma. Contemp Oncol (Pozn) 17: 150-155, 2013.

23. Chassagnon G, Bennani S and Revel MP: New TNM classification of non-small cell lung cancer. Rev Pneumol Clin 73: 34-39, 2017 (In French)

24. Harms A, Kriegsmann M, Fink L, Länger F and Warth A: The new TNM classification for lung tumors: Changes and the assessment of multiple tumor foci. Pathologe 38: 11-20, 2017 (In German).

25. Tang D, Xu S, Zhang Q and Zhao W: The expression and clinical significance of the androgen receptor and E-cadherin in triple-negative breast cancer. Med Oncol 29: 526-533, 2012.

26. Gao L, Antic T, Hyjek E, Gong C, Mueller J, Waxman I, DeMay RM and Reeves W: Immunohistochemical analysis of E-cadherin and zeste homolog 2 expression in endoscopic ultrasound-guided fine-needle aspiration of pancreatic adenocarinoma. Cancer Cytopathol 121: 644-652, 2013.

27. Elzagheid A, Buhmeida A, Laato M, El-Faitori O, Syrjänen K, Collan Y and Pyrhönen S: Loss of E-cadherin expression predicts disease recurrence and shorter survival in colorectal carcinoma. APMIS 120: 539-548, 2012.

28. Zhai B, Yan HX, Liu SQ, Chen L, Wu MC and Wang HY: Reduced expression of E-cadherin/catenin complex in hepatocellular carcinomas. World J Gastroenterol 14: 5665-5673, 2008

29. Ling C, Raasch JL and Welham NV: E-cadherin and transglutaminase-1 epithelial barrier restoration precedes type IV collagen basement membrane reconstruction following vocal fold mucosal injury. Cells Tissues Organs 193: 158-169, 2011.

30. Molina-Ortiz I, Bartolomé RA, Hernández-Varas P, Colo GP and Teixidó J: Overexpression of E-cadherin on melanoma cells inhibits chemokine-promoted invasion involving p190RhoGAP/p120ctn-dependent inactivation of RhoA. J Biol Chem 284: 15147-15157, 2009.

31. Larriba MJ, Casado-Vela J, Pendás-Franco N, Peña R, García de Herreros A, Berciano MT, Lafarga M, Casal JI and Muñoz A: Novel snaill target proteins in human colon cancer identified by proteomic analysis. PLoS One 5: e10221, 2010.

32. Tong S, Xia T, Fan K, Jiang K, Zhai W, Li JS, Wang SH and Wang JJ: $14-3-3 \zeta$ promotes lung cancer cell invasion by increasing the Snail protein expression through atypical protein

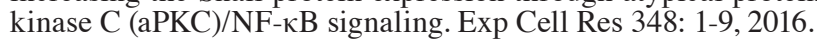

33. Campbell PM and Der CJ: Oncogenic Ras and its role in tumor cell invasion and metastasis. Semin Cancer Biol 14: 105-114, 2004

34. Lee JY, Lowell CA, Lemay DG, Youn HS, Rhee SH, Sohn KH, Jang B, Ye J, Chung JH and Hwang DH: The regulation of the expression of inducible nitric oxide synthase by Src-family tyrosine kinases mediated through MyD88-independent signaling pathways of Toll-like receptor 4. Biochem Pharmacol 70 : $1231-1240,2005$

35. Pautz A, Art J, Hahn S, Nowag S, Voss C and Kleinert H: Regulation of the expression of inducible nitric oxide synthase. Nitric Oxide 23: 75-93, 2010.

36. Hollestelle A, Peeters JK, Smid M, Timmermans M, Verhoog LC, Westenend PJ, Heine AA, Chan A, Sieuwerts AM, Wiemer EA, et al: Loss of E-cadherin is not a necessity for epithelial to mesenchymal transition in human breast cancer. Breast Cancer Res Treat 138: 47-57, 2013.

37. Chen A, Beetham H, Black MA, Priya R, Telford BJ, Guest J, Wiggins GA, Godwin TD, Yap AS and Guilford PJ: E-cadherin loss alters cytoskeletal organization and adhesion in non-malignant breast cells but is insufficient to induce an epithelial-mesenchymal transition. BMC Cancer 14: 552, 2014.

38. Ahn SM, Cha JY, Kim J, Kim D, Trang HT, Kim YM, Cho YH, Park D and Hong S: Smad 3 regulates E-cadherin via miRNA-200 pathway. Oncogene 31: 3051-3059, 2012.

39. Mise N, Savai R, Yu H, Schwarz J, Kaminski N and Eickelberg O: Zyxin is a transforming growth factor- $\beta$ (TGF- $\beta$ )/Smad 3 target gene that regulates lung cancer cell motility via integrin $\alpha 5 \beta 1$. J Biol Chem 287: 31393-31405, 2012.

40. Zhao GY, Ding JY, Lu CL, Lin ZW and Guo J: The overexpression of 14-3-3 5 and Hsp27 promotes non-small cell lung cancer progression. Cancer 120: 652-663, 2014

41. Chen HH, Wang Y, Xu YJ, Du ZY, Hao HJ, Xu DY, Tan XG, Lin HY and Lu YL: Inhibition of metastasis of lung cancer cells by $14-3-3 \zeta$ protein:an experimental investigation. Bull Acad Milit, 2005 .

42. An N, Zhu W, Feng Z, Ye S, Yu C and Cai C: Effect of 20(R) ginsenoside $\mathrm{Rg} 3$ on protein expression of lung cancer cell line. Zhongguo Fei Ai Za Zhi 11: 311-320, 2008 (In Chinese). 
43. Schneider BJ and Kalemkerian GP: Personalized therapy of small cell lung cancer. Adv Exp Med Biol 890: 149-174, 2016.

44. Zhu P, Sang Y, Xu H, Zhao J, Xu R, Sun Y, Xu T, Wang X, Chen L, Feng H, et al: ADAM22 plays an important role in cell adhesion and spreading with the assistance of 14-3-3. Biochem Biophys Res Commun 331: 938-946, 2005.

45. Kobayashi R, Deavers M,Patenia R, Rice-Stitt T, Halbe J, Gallardo S and Freedman RS: 14-3-3 zeta protein secreted by tumor associated monocytes/macrophages from ascites of epithelial ovarian cancer patients. Cancer Immunol Immunother 58: 247-258, 2009.

46. Fan T, Li R, Todd NW, Qiu Q, Fang HB, Wang H, Shen J, Zhao RY, Caraway NP, Katz RL, et al: Up-regulation of 14-3-3zeta in lung cancer and its implication as prognostic and therapeutic target. Cancer Res 67: 7901-7906, 2007.
47. Khorrami A, Sharif Bagheri M, Tavallaei M and Gharechahi J: The functional significance of 14-3-3 proteins in cancer: Focus on lung cancer. Horm Mol Biol Clin Investig 32: pii: /j/hmbci.2017.32. issue-3/hmbci-2017-0032/hmbci-2017-0032.xml, 2017.

48. Cau Y, Valensin D, Mori M, Draghi S and Botta M: Structure, function, involvement in diseases and targeting of 14-3-3 proteins: An update. Curr Med Chem 25: 5-21, 2018.

49. Ko S, Kim JY, Jeong J, Lee JE, Yang WI and Jung WH: The role and regulatory mechanism of 14-3-3 sigma in human breast cancer. J Breast Cancer 17: 207-218, 2014. 